University of New Hampshire

University of New Hampshire Scholars' Repository

Space Science Center

Institute for the Study of Earth, Oceans, and

Space (EOS)

2001

\title{
X-and gamma-ray observations of the 15 November 1991 Solar Flare
}

\author{
M B. Arndt \\ University of New Hampshire - Main Campus \\ A Connors \\ University of New Hampshire - Main Campus \\ J Lockwood \\ University of New Hampshire - Main Campus \\ Mark L. McConnell \\ University of New Hampshire - Main Campus, mark.mcconnell@unh.edu \\ R Suleiman \\ University of New Hampshire - Main Campus
}

See next page for additional authors

Follow this and additional works at: https://scholars.unh.edu/ssc

Part of the Astrophysics and Astronomy Commons

\section{Recommended Citation}

X- and gamma-ray observations of the 15 November 1991 Solar Flare Arndt, M. B. and Connors, A. and Lockwood, J. and McConnell, M. and Suleiman, R. and Ryan, J. and Young, C. A. and Rank, G. and Schönfelder, V. and Debrunner, H. and Bennett, K. and Williams, O. and Winkler, C., AIP Conference Proceedings, 587, 618-622 (2001), DOI:http://dx.doi.org/10.1063/1.1419473

This Conference Proceeding is brought to you for free and open access by the Institute for the Study of Earth, Oceans, and Space (EOS) at University of New Hampshire Scholars' Repository. It has been accepted for inclusion in Space Science Center by an authorized administrator of University of New Hampshire Scholars' Repository. For more information, please contact Scholarly.Communication@unh.edu. 


\section{Authors}

M B. Arndt, A Connors, J Lockwood, Mark L. McConnell, R Suleiman, James M. Ryan, C A. Young, G Rank, V Schonfelder, H Debrunner, K Bennett, O R. Williams, and C Winkler 


\section{AIP | Proceedings}

\section{$X$ - and gamma-ray observations of the 15 November 1991 Solar Flare}

M. B. Arndt, A. Connors, J. Lockwood, M. McConnell, R. Suleiman, J. Ryan, C. A. Young, G. Rank, V.

Schönfelder, H. Debrunner, K. Bennett, O. Williams, and C. Winkler

Citation: AIP Conference Proceedings 587, 618 (2001); doi: 10.1063/1.1419473

View online: http://dx.doi.org/10.1063/1.1419473

View Table of Contents: http://scitation.aip.org/content/aip/proceeding/aipcp/587?ver=pdfcov

Published by the AIP Publishing

\section{Articles you may be interested in}

Expected gamma-ray fluxes from interactions of flare energetic particles with solar wind matter AIP Conf. Proc. 587, 628 (2001); 10.1063/1.1419475

Solar gamma-ray physics comes of age

AIP Conf. Proc. 587, 603 (2001); 10.1063/1.1419471

CGRO observations of gamma-ray flares associated with ACE particle events

AIP Conf. Proc. 528, 185 (2000); 10.1063/1.1324309

Gamma ray measurements of the 1991 November 15 solar flare

AIP Conf. Proc. 510, 569 (2000); 10.1063/1.1303267

Energetic proton spectra in the 11 June 1991 solar flare

AIP Conf. Proc. 510, 564 (2000); 10.1063/1.1303266 


\title{
X- and Gamma-Ray Observations of the 15 November 1991 Solar Flare
}

\author{
M. B. Arndt ${ }^{1}$, A. Connors ${ }^{1}$, J. Lockwood ${ }^{1}$, M. McConnell ${ }^{1}$, R. Suleiman ${ }^{1}$, \\ J. Ryan ${ }^{1}$, C.A. Young ${ }^{1}$, G. Rank ${ }^{2}$, V. Schönfelder ${ }^{2}$, H. Debrunner ${ }^{3}$, K. \\ Bennett $^{4}, \mathrm{O}$. Williams ${ }^{4}$, and C. Winkler ${ }^{4}$ \\ ${ }^{1}$ University of New Hampshire, ${ }^{2}$ Max Plank Inst. für Extraterrestrische Physik, ${ }^{3}$ Univ. Bern \\ ${ }^{4}$ SSD/ESTEC
}

\begin{abstract}
This work expands the current understanding of the 15 November 1991 Solar Flare. The flare was a well observed event in radio to gamma-rays and is the first flare to be extensively studied with the benefit of detailed soft and hard X-ray images. In this work, we add data from all four instruments on the Compton Gamma Ray Observatory. Using these data we determined that the accelerated electron spectrum above $170 \mathrm{keV}$ is best fit with a power law with a spectral index of -4.6 , while the accelerated proton spectrum above $0.6 \mathrm{MeV}$ is fit with a power law of spectral index -4.5 . From this we computed lower limits for the energy content of these particles of $\sim 10^{23} \mathrm{ergs}$ (electrons) and $\sim 10^{27} \mathrm{ergs}$ (ions above $0.6 \mathrm{MeV}$ ). These particles do not have enough energy to produce the white-light emission observed from this event. We computed a time constant of $26_{-15}^{+20} \mathrm{~s}$ for the $2.223 \mathrm{MeV}$ neutron capture line, which is consistent at the $2 \sigma$ level with the lowest values of $\sim 70 \mathrm{~s}$ found for other flares. The mechanism for this short capture time may be better understood after analyses of high energy EGRET data that show potential evidence for pion emission near $\sim 100 \mathrm{MeV}$.
\end{abstract}

\section{INTRODUCTION}

The goals of this dissertation work were to add to the extant body of knowledge of the 15 November 1991 solar flare in two ways: by analyzing high-energy data from the Compton Gamma Ray Observatory (CGRO) that have been underutilized in previous studies and by applying another flare model to explain the most intense highenergy emission from the event. In these proceedings we only have space to discuss the CGRO data and analyses.

This X1.5 event was a well observed flare in a broad range of wavelengths [1-26] and is the first to be extensively studied with the benefit of detailed X-ray images. This flare was located near disk center and lasted on the order of minutes in X-rays.

\section{DATA ANALYSIS}

COMPTEL data analysis was done using the Maximum Entropy Method (MEM). In this method, a test photon spectrum is folded through an instrument response and 
compared to the measured count spectrum using a $\chi^{2}$ test. EGRET photon spectra were also generated by a MEM approach.

BATSE data were fit with a double power law where $E_{B}$ is the break energy:

$$
I(E) \propto\left\{\begin{array}{l}
E^{-\gamma_{1}} \text { for } E<E_{B} \\
E^{-\gamma_{2}} \text { for } E>E_{B}
\end{array}\right.
$$

\section{RESULTS}

Figure 1 is a composite spectrum from the impulsive phase (22:36:36 - 22:38:14 UT) of the flare. All data are background subtracted. The BATSE curve $(0.2-10$ $\mathrm{MeV})$ is an extrapolated fit where $\gamma_{2}=-3.6$. The discrepancy between COMPTEL $(0.6-10 \mathrm{MeV})$ and EGRET $(1-300 \mathrm{MeV})$ spectra near $10 \mathrm{MeV}$ and the emission near $60 \mathrm{MeV}$ are most likely due to background subtraction issues with EGRET data.

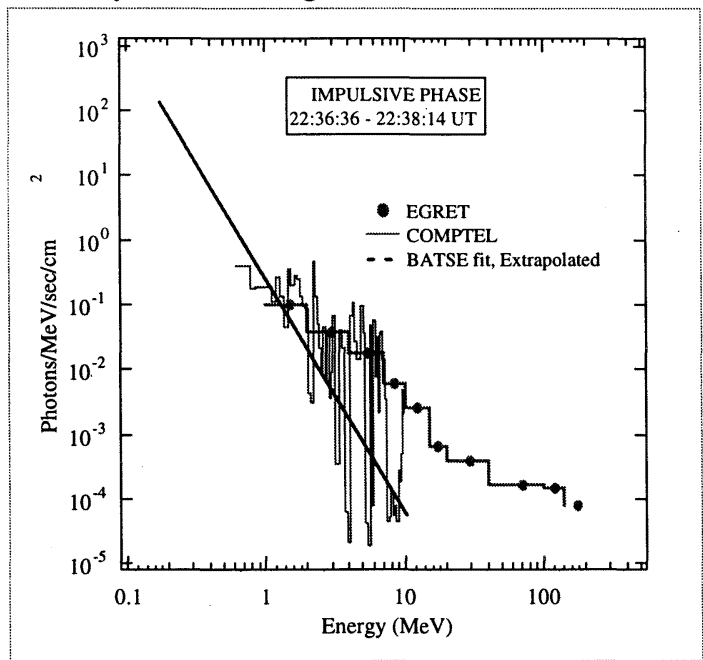

FIGURE 1. Composite Spectrum of the impulsive phase of the 15 November 1991 solar flare.

\section{Accelerated Protons}

Using fluences derived from COMPTEL spectra we are able to deduce the shape of the accelerated proton spectrum. Two accelerated proton spectra shapes are considered: the Bessel function, parameterized by $\alpha \mathrm{T}$ and the power law, parameterized by s. Our values (bold) and previously published values of $\alpha \mathrm{T}$ and $\mathrm{s}$ [27-29] are listed in Table 1 along with fluence ratios derived from several highenergy emission lines. 
The proton spectrum above $0.6 \mathrm{MeV}$ is best fit with a power law of $\mathrm{s}=-4.5$. The energy content of these ions is $\sim 10^{27}$ ergs. These particles do not have enough energy to produce the observed white light emission, which has an energy content on the order of $10^{30}$ ergs[6].

TABLE 1. Shape of accelerated proton spectra.

\begin{tabular}{cccc}
\hline Fluence Line Ratio & Value & $\alpha \mathbf{T}$ & $\mathbf{s}$ \\
\hline$\phi_{4.4} / \phi_{0.42}$ & $0.035-0.065[13]$ & -- & -- \\
$\phi_{4.4} / \phi_{2.223}$ & $\mathbf{0 . 5 2} \pm \mathbf{0 . 1 4}$ & $0.009 \pm 0.002[11-12]$ & $\mathbf{4 . 5 - 5}$ \\
$\phi_{4-7} / \phi_{2.223}$ & $\mathbf{1 . 6} \pm \mathbf{0 . 3 4}$ & $\mathbf{0 . 0 0 8 - 0 . 0 1 5}$ & $\mathbf{4 - 5}$ \\
$\phi_{4-7} / \phi_{2.223}$ & -- & $0.010 \pm 0.002[25]$ & $\mathbf{4 - 5}$ \\
$\phi_{4.4} / \phi_{6.13}$ & $\mathbf{2 . 1 1} \pm \mathbf{0 . 4 7}$ & -- & -- \\
$\phi_{1.63} / \phi_{6.13}$ & $\mathbf{4 . 9 5} \pm \mathbf{1 . 0}$ & -- & $\mathbf{4 . 5 - 5 . 5}$ \\
\hline
\end{tabular}

\subsection{MeV Emission}

Using emission between 3.956 and $7.055 \mathrm{MeV}$ as a template for the neutron production rate $\mathrm{S}\left(\mathrm{t}^{\prime}\right)$, we compute the $2.223 \mathrm{MeV}$ time constant $\tau$ using the expression

$$
F_{2.223 \mathrm{MeV}}(t) \propto \int_{-\infty}^{t} S\left(t^{\prime}\right) e^{-\left(t-t^{\prime}\right) \tau} d t^{\prime}
$$

This time constant $\tau$ is a function of the neutron decay time as well as proton and ${ }^{3} \mathrm{He}$ neutron capture times. Subsequently, $\tau$ can provide information about proton and ${ }^{3} \mathrm{He}$ densities. We found the best fit to be $26_{-15}^{+20} \mathrm{~s}$, which is consistent at the $2 \sigma$ level with values of $\sim 70 \mathrm{~s}$ found for other flares.

A low value of $\tau$ suggests the presence of either an unusually high ${ }^{3} \mathrm{He}$ abundance or that neutron capture is occurring in a dense environment where neutrons thermalize and are quickly captured on ${ }^{1} \mathrm{H}$.

Given our $\tau$ and a typical chromospheric density, we find a ${ }^{3} \mathrm{He} / \mathrm{H}$ abundance ratio nearly an order of magnitude higher than values computed for other flares, but in agreement with recent results [30].

The white light emission from this flare suggests that very high energy protons are penetrating into the photosphere. The neutrons created in this dense layer would be captured quickly, also resulting in a low $\tau$.

\section{Accelerated Electrons}

Table 2 is a summary of spectral indices from various instruments. Included are satellite viewing angles, power law spectral indices below $\left(\gamma_{1}\right)$ and above $\left(\gamma_{2}\right)$ break energies. If error bars are not included, they were not present in the literature. The data do not all agree within error bars, however the discrepancies may be explained by the different viewing angles of each instrument. We use the indices derived from BATSE data in our work. The energy content (lower limit) from electrons above $170 \mathrm{keV}$ is $\sim 10^{23}$ ergs. 
TABLE 2. Spectral Indices of Accelerated Electrons During Impulsive Phase.

\begin{tabular}{|c|c|c|c|}
\hline Satellite (Viewing Angle) & $\gamma_{1}$ & $\mathbf{E}_{\mathrm{B}}(\mathrm{KeV})$ & $\gamma_{2}$ \\
\hline $\operatorname{BATSE}\left(\sim 20^{\circ}\right)$ & $2.66 \pm 0.27$ & $168 \pm 51$ & $3.61 \pm 0.23$ \\
\hline $\operatorname{OSSE}\left(\sim 20^{\circ}\right)$ & $3.0 \pm 0.7$ & 100 & -- \\
\hline Yohkoh $\left(20^{\circ}\right)$ & $\begin{array}{c}2-4.5[19] \\
3.7 \pm 0.3[31]\end{array}$ & 93 & -- \\
\hline $\operatorname{PVO}\left(\sim 52^{\circ}\right)$ & -- & 150 & $3.37 \pm 0.05[15]$ \\
\hline Ulysses $\left(\sim 80^{\circ}\right)$ & $3.08[8]$ & $166\left(\gamma_{1}\right), 150\left(\gamma_{2}\right)$ & $2.72 \pm 0.07[15]$ \\
\hline Yohkoh (HXS) & $3.20[8]$ & 87 & $\begin{array}{c}3.82[2] \\
3.70 \pm 0.03[15]\end{array}$ \\
\hline Yohkoh (HXT) & $3.39[8]$ & 93 & -- \\
\hline
\end{tabular}

\section{CONCLUSIONS}

Our goals with this work were to add to the extant body of knowledge of the 15 November 1991 solar flare by introducing new high-energy data from the CGRO.

These data allowed us to confirm previous results and to compute the $2.223 \mathrm{MeV}$ time constant, which is consistent (but only at the $2 \sigma$ level) with the lowest values computed for other flares. We computed the accelerated particle spectra and subsequent energy content of these particles. We also found that the accelerated protons do not have enough energy to produce the observed white light emission.

\section{Future Work}

Once we have had the opportunity to analyze EGRET data in more depth we will further improve our understanding of the high-energy particle dynamics within this flare. If EGRET does observe extended pion emission we have further evidence that high-energy protons are reaching deep into the chromosphere or photosphere. This extended pion emission would also allow us to reclassify this event as a long duration gamma-ray flare.

The 15 November 1991 solar flare was unique because it was observed in a broad energy range with detailed X-ray images. We look forward to HESSI providing us with similarly well observed events.

\section{ACKNOWLEDGMENTS}

I would like to thank my advisor Dr. J. M. Ryan and my other committee members (Drs. M. McConnell, J. Hollweg, S. Habbal, and D. Meredith) for their help and support. I would also like to thank Drs. T. Sakao, M. Lee, T. Forbes, R. Murphy, H. Debrunner, and M. Yoshimori for our enlightening conversations. I would also like to acknowledge R. Murphy (OSSE), M. Yoshimori (YOHKOH), D. Bertsch (EGRET), and R. Schwartz (BATSE) for their help and access to data. This work was funded by the University of New Hampshire, a NASA Space Grant and NASA grants NAG52350, NAG5-7179, NAG5-3802, and NAS5-26645. 


\section{REFERENCES}

1. Aschwanden, M.J., Kosugi, T., Hudson, H.S., Wills, M.J., and Schwartz, R.A., Astrophys.J, 470, 1198, (1996).

2. Aschwanden, M.J., Wills, M.J., Hudson, H.S., Kosugi, T., and Schwartz, R.A., Astrophys.J, 468,398,(1996).

3. Canfield, R.C., Hudson, H., Leka, K.D., Mickey, D.L., Metcalf, T.R., Wuelser, J.-P., Acton, L.W., Strong, K.K.T., Kosugi, T., Sakao, T., Tsuneta, S., Culhane, J.L., Phillips, A., and Fludra, A., Publ. Astron. Soc. Japan., 44, No.5, L111, (1992).

4. Canfield, R.C. and Reardon, K.P., Sol. Phys., 182, 145, (1998).

5. Culhane, J.L., et al., Adv. Space Res., 13, No. 9, 303, (1993).

6. Hudson, H.S., Acton, L.W., Hirayama, T., and Uchida, Y., Publ. Astron. Soc. Japan, 44, No. 5, L77, (1992).

7. Inda-Koide, M., Makishima, K., Kosugi, T., and Kaneda, H., Publ. Astron. Soc. Japan, 47, 661, (1995).

8. Kane, S.R., Hurley, K., McTiernan, J.M., Boer, M., Niel, M., Kosugi, T., and Yoshimori, M., Astrophys.J, 500,1003, (1998).

9. Kane, S.R., Hurley, K., McTiernan, and J.M, Sommer, M., Adv. Space Res. 13, No. 9, 241, (1993).

10. Kane, S.R., McTiernan, J.M., Loran, J., Lemen, J., Yoshimori, M., Ohki, K., and Kosugi, T., Adv. Space Res., 13, No. 9, 237, (1993).

11. Kawabata, K., Yohimori, M., Suga, K., Morimoto, K., Hiraoka, T., Sato, J., and Ohki, K., Astrophys.J Suppl. Ser., 90, 701, (1994).

12. Kawabata, K., Yohimori, M., Suga, K., Morimoto, K., Hiraoka, T., Sato, J., and Ohki, K., in Proceedings of Kofu Symposium, NRO Report No. 360, 123, (1994).

13. Kotov, YU.D., Bogovalov, S.V., Endalova, O.V., and Yoshimori, M., Astrophys.J, 473, 514, (1996).

14. Matthews, S.A., Brown, J.C., and van Driel-Gesztelyi, L., Astron. Astrophys., 340, 277, (1998).

15.McTiernan, J.M., Kane, S.R., Hurley, K., Laros, J.G., Fenimore, E.E., Klebsadel, R.W., Sommer, M., and Yoshimori, M., in Proceedings of Kofu Symposium, NRO Report No. 360, 389, (1994).

16. Sakao, T., Ph.D. Thesis, National Astronomical Observatory, Japan, (1994).

17. Sakao, T., Kosugi, T., and Masuda, S., in Proceedings of Observational Plasma Astrophysics, Five Years of Yohkoh and Beyond, Kluwer Academic Publishers, (1998).

18. Sakao, T., et al., Publ. Astron. Soc. Japan, 44, No. 5, L83, (1992).

19.Sakao, T., Kosugi, T., Masuda, S., Yaji, K., Inda-Koide, M., and Makishima, K., in Proceedings of Kofu Symposium, NRO Report No. 360, 169, (1994).

20. Sylwester, B. and Sylwester J., Evolution of Yohkoh Observed White Light Flares, Kluwer Academic Publishers, 2000 (in press).

21. Takakura, T., Kosugi, T., Sakao, T., Makishima, K., Inda-Koide, M., and Masuda, S., Publ. Astron. Soc. Japan, 47, 355, (1995).

22.Wülser, J.-P., Canfield, R.C., Acton, L.W., Culhane, J.L., Phillips, A., Fludra, A.J., Sakao, T., Masuda, S., Kosugi, T., and Tsuneta, S., Astrophys.J, 424, No.1, 459, (1994).

23. Yoshimori, M., Kawabata, K., and Ohki, K., in Proceedings of the XXIII International Cosmic Ray Conference, University of Calgary, (1993):

24. Yoshimori, M., Morimoto, K., Suga, K., and Matsuda, T., in Magnetodynamic Phenomena in the Solar Atmosphere - Prototypes of Stellar Magnetic Activity, Kluwer Academic Publishers, (1996).

25. Yoshimori, M., Suga, K., Morimoto, K., Hiroko, T., Sato, J., Kawabata, K., and Ohki, K., Astrophys.J Suppl. Ser., 90, 639, (1994).

26. Yoshimori, M., Takai, Y., Morimoto, K., Suga, K., and Ohki, K., Publ. Astron. Soc. Japan, 44, No. 5, L107, (1992).

27. Ramaty, R., Mandzhavidze, N., and Kozlovsky, B., in Proceedings of High Energy Sol. Phys., Greenbelt Maryland, AIP \# 374, (1995).

28. Ramaty, R., Mandzhavidze, N., Kozlovsky, B., and Murphy, R.J., Astrophys.J Lett., 455, L193, (1995).

29. Ramaty, R., Mandzhavidze, N., Kozlovsky, B., and Skibo, J.G., Adv. Space. Res, 13, 275, (1993).

30.Young, C.A., these proceedings.

31.Yoshimori, M. personal communication, (2000). 